\title{
Microcosm responses to environmental perturbants
}

\author{
An extension of baseline field survey
}

\author{
E. C. Evans III \\ Naval Undersea Center, Hawaii Laboratory; \\ Kailua, Hawaii, USA
}

\begin{abstract}
A flow-through microcosm facility using unfiltered ocean source water is described. "Stagnation" cleaning has proven to be a simple and effective way of maintaining seawater distribution systems free of fouling organisms and is recommended. A valveless system for regulating water flow is also recommended. The microcosm facility has been used experimentally as an extension of field surveys being conducted in Hawaiian harbors. Examples of two essentially different types of microcosm experiments are presented to illustrate this interactive approach to environmental research. One approach disturbs an established microcosm community with specific environmental perturbants and follows both the community response and recovery over prolonged time periods. Examples of perturbation by elevated nutrients and by elevated copper concentrations are given. The ability of reef flat communities to trap and retain phosphorus even in a flow-through system is demonstrated. Added copper is shown to result in a number of responses not seen in the legislatively-preferred copper toxicity tests. The second approach involves transferring substrates from the field into the microcosm and following response with time. Again, two examples are given - one involving the transfer of fouling panels, the other, of sediments. Profound changes are seen when fouling panels are transferred from a high-nutrient into a low-nutrient environment. Nutrient-rich sediments, however, are shown not to influence water-column nutrient concentrations in the microcosms, but do acquire increased infaunal populations over a 3 -month period. Finally, an example of how the findings of the microcosm experiments are applied in the field is provided. The case is made that although this approach necessarily involves multivariate experimental preparations which sometimes lack precision, it is nevertheless a required and fruitful procedure in the search for better understanding of the environmental dynamics of harbor communities.
\end{abstract}

\section{INTRODUCTION}

The U.S. Navy must operate in many major ports of the world, most of which contain important ecosystems already under severe environmental stress. As a user of harbors, the Navy has recognized its share in the responsibility to seek practical means of alleviating these stresses. In consequence, a program designed to assess harbor condition and to determine biological response to various environmental perturbants was initiated several years ago (Hura, 1976). The need to learn what pollution or toxicity means at the ecosystems level and to recognize "vital signs" of normally functioning 
harbors is appreciated. The major thrust of the Navy program has been to improve ecological inventorying techniques (baseline field survey) through the use of bioindicator systems. Central to this effort has been the development of microcosms as an interactive part of the field survey process. The purpose of this paper is to describe the microcosm facility developed and to present some examples of how it has been used.

Although the term "microcosm" is of relatively recent origin, use of microcosms is certainly not new. The idea first took the form of a chemostat (Monod, 1950). The term is used here to designate a contained and often simplified marine community on which controlled experiments can be performed. The microcosms used are the flowthrough, unfiltered type, and, as such, can be considered true extensions of the natural world since: (a) normal diel variations in ambient conditions are duplicated, (b) natural foods and recruitment are provided, (c) normal seasonal variations are followed and natural seral development occurs, and (d) wastes, biogenic toxins, hormones, and pheromones are kept at near-natural levels. Microcosms thus represent an excellent transitional stage between the precision of laboratory experiments and the realism of in situ field observations. As an experimental subject, an established microcosms may be regarded as a functional marine community with its normal resistance to insult and its recovery capacity intact.

\section{THE ULUPAU MICROCOSM FACILITY}

The microcosm facility constructed by the Naval Undersea Center at Ulupau, Hawaii was modeled after a similar system developed and built by the Hawaii Institute of Marine Biology, University of Hawaii; both locations are shown in Figure 1. The Ulupau facility, described in detail elsewhere (Henderson, 1976), is supplied with clean seawater drawn at just-subtidal levels from the edge of an oceanic reef fringing Ulupau Head. With the exception of the titanium pump-shaft sleeves and four 3-inch Y-fittings of $\mathrm{ABS}^{*}$ plastic, all materials used in the seawater distribution system are PVC* plastic. Seawater is continuously pumped at $3901 \mathrm{~min}^{-1}$ through 85 meters of supply lines into a 1400-liter reservoir located 17 meters above MLLW. The microcosm containers are a series of twelve 500-1, gel-coated fiberglass tanks continuously supplied by gravity flow with unfiltered seawater at any desired rate up to $151 \mathrm{~min}^{-1}$. Tank interiors are brown, exteriors are white. The tanks are placed on a deck $2 \frac{1}{2} \mathrm{~m}$ above the ground (Fig. 2) to assure continuous exposure to full sunlight and also to facilitate access to the considerable plumbing servicing them. The tanks are so plumbed that each has essentially the same length of supply and discharge piping; thus, bias due to pipe-residence-time is avoided. Corals can be maintained in a healthy, growing state indefintely in these microcosms.

Two innovations in facility design are worth special attention. The first is the use of "stagnation" cleaning to keep all supply lines free of sessile, filter-feeding organisms, an important facility requirement since food and unaltered recruitment

\footnotetext{
$* \mathrm{ABS}=$ acrylonitrile-butadiene-styrene; $\mathrm{PVC}=$ polyvinyl-chloride.
} 


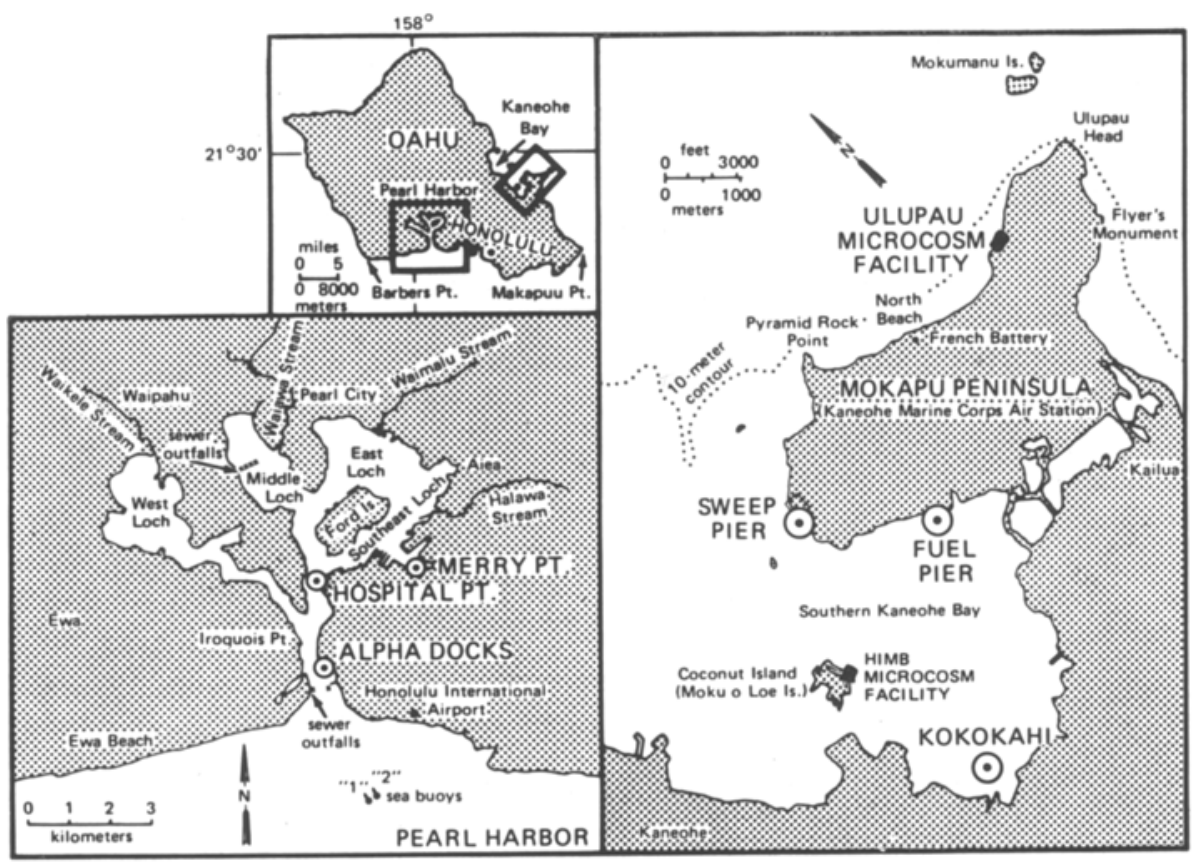

Fig. 1: Location of Microcosm Facilities at Ulupau and at Hawaii Institute of Marine Biology on the island of Oahu, Hawaii

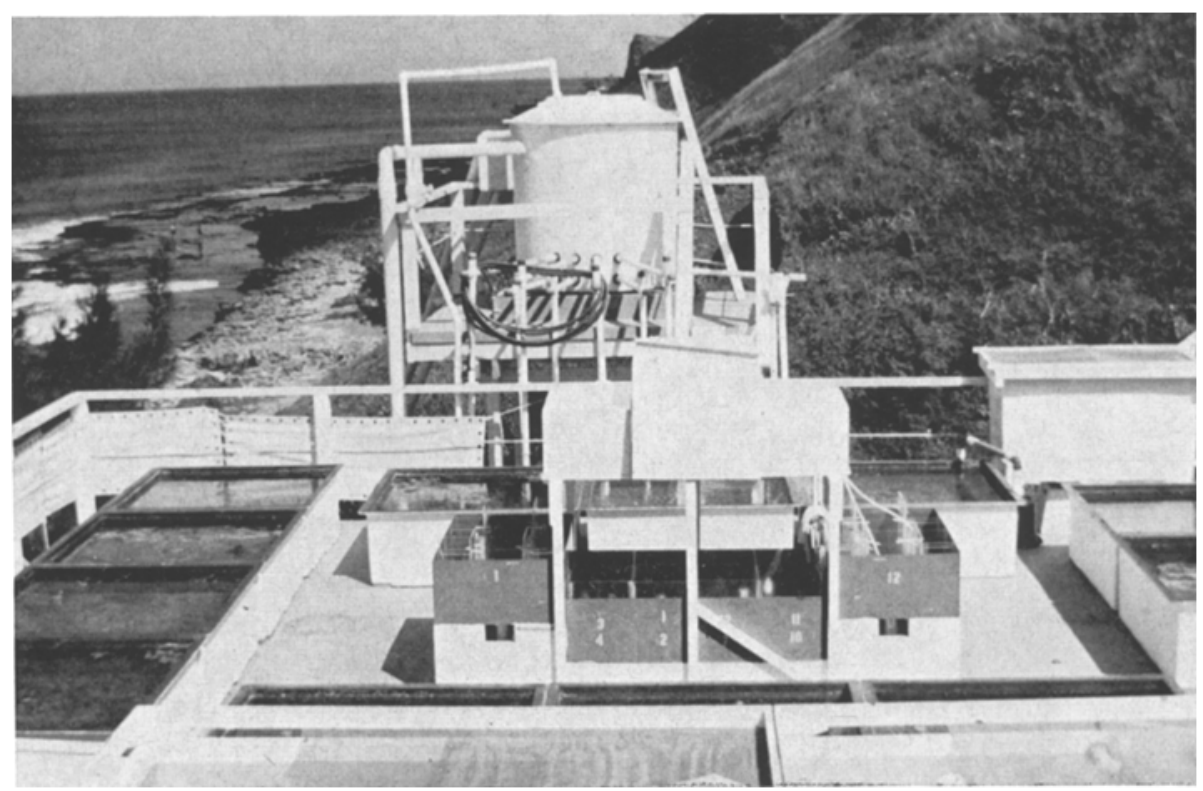

Fig. 2: The microcosm deck at Ulupau, showing the 1400-1 reservoir and the inlet-box/outletbox distribution system (April 1975) 
populations must reach the microcosms. The entire seawater system is double plumbed. One supply system is used for a 7-day interval, while the unused system is allowed to become anoxic. Any organisms that settled during the previous 7 -day interval die and putrify. This organic debris is easily backflushed out of the system just prior to putting it back into use. The Ulupau seawater supply system has been kept free of all fouling organisms since February 1975 by means of this simple transfer procedure, a half-hour operation required once a week. For those wishing to construct flowthrough facilities using ocean source water, it is highly recommended.

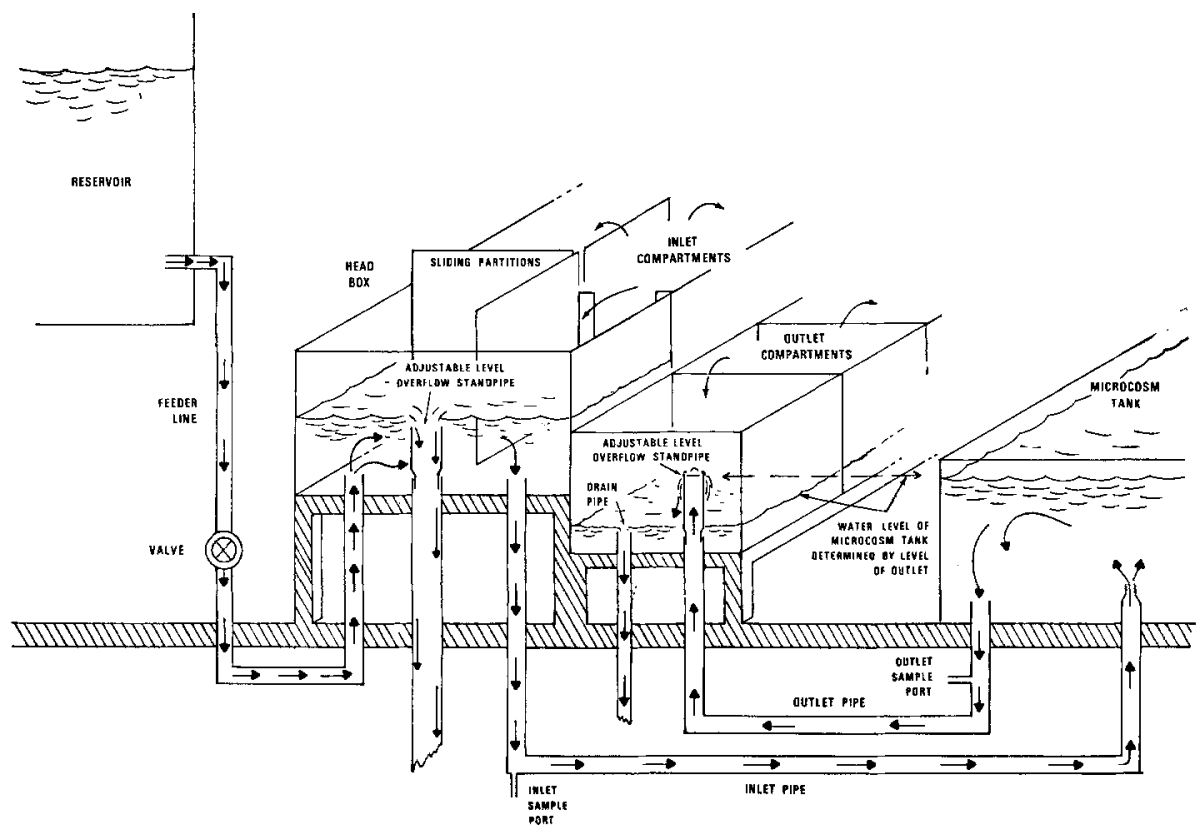

Fig. 3: Sketch of inlet-box/outlet-box system for distributing seawater to microcosm tanks

The second innovation is the inlet-box/outlet-box system shown in Figure 3. This is a centrally-located arrangement of weirs, standpipes, and intermittant siphons used to regulate seawater flow rates through each of the twelve microcosm tanks. The difference in water level between the inlet and outlet boxes servicing a given tank determines flow rate through that tank. Water level differences are easily set and maintained by means of overflow standpipes and intermittent siphons. Each tank can receive a separate water supply or, by adjusting an arrangement of sliding panels, tanks may be combined or ganged in various ways. Furthermore, inlet or outlet water samples can be drawn from the appropriate boxes or various experimental additives (silt, nutrients, or heavy metals) can be conveniently introduced at the inlet boxes. Again, the arrangement has provided simple, trouble-free, yet precise flow-regulation for over $1 \frac{1}{2}$ years since the Ulupau facility began operation. 


\section{PRELIMINARY RESULTS}

The Ulupau facility has been used for two essentially different kinds of experiments. One type of experiment subjects an established, naturally-recruited microcosm to experimentally introduced perturbants. The other type involves transferring various marine communities settled in the field into the microcosm tanks. Both experimental approaches require long time periods and, because of the limited facilities, have low replicaticn. It is also obvious that microcosms represent multivariate and hence loose experimental preparations which do not always lend themselves to high precision. This situation can at times be exasperating, but it is one that must be coped with if environmental perturbants are to be understood at the ecosystems level. For these various reasons, the observations reported here for the first time in the open literature must be considered preliminary.

\section{Elevated nutrients}

Certain initial studies (Henderson, 1976) indicated significant differences in net oxygen production between microcosms naturally settled at Ulupau (ocean source water) and at the Hawaii Institute (bay source water). The principal reason for this difference appeared to be a 2 -fold increase in available phosphate in the latter source water. To test this observed difference further, six 5-month-old, naturally-recruited microcosms* were used in an elevated nutrient experiment. Two tanks were used as controls, two received nitrogen (added as $\mathrm{NH}_{4} \mathrm{Cl}$ ), and two received phosphorus (added as $\mathrm{KH}_{2} \mathrm{PO}_{4}$ ). Flow rates through all six microcosms were held at about $101 \mathrm{~min}^{-1}$, and the flow of nutrient stock solutions into the inlet boxes was adjusted to add $8 \mu \mathrm{g}$-at $1^{-1}$ of $\mathrm{N}$ and $\mathrm{P}$ respectively to the flow-through waters. Nutrient exposures lasted about two months (Sep.-Oct., 1975). Measurements of community metabolism\%* were made during the nutrient additions and for about four months after the additions ceased. Some of the results are presented in Table 1; the differences plotted in Figure 4 are statistically significant $(P=0.01)$. The microcosms definitely respond to added nutrients, exhibiting greater than $50 \%$ increase in net oxygen production $\left(4 \mathrm{O}_{2}\right)$ as well as increased chlorophyll-a production and biomass. As is seen in Figure 4, elevated phosphate also increases ammonia uptake, whereas elevated ammonia results in loss of phosphate, suggesting that ammonia-N at $8 \mu \mathrm{g}^{-a t} \mathrm{I}^{-1}$ is somewhat toxic to reef-flat-settled microcosms. None of the nutrient additions caused

* Naturally recruited microcosms contain too many organisms to be enumerated here (see Henderson, 1976). Tanks with coral rubble, sand, and 4 terra-cotta tiles as added substrate, when settled at Ulupau, can contain about 60 kinds of algae and 200 kinds of invertebrates; dominant macroforms usually include: 4 to 5 species of algae, 5 different sea hares, 4 to 5 kinds of xanthid and portunid crabs, 3 species of alpheid plus several kinds of caridean shrimp, about 12 different molluscs, 10 kinds of polychaete worms, 3 species of holothurians, and a number of coelenterates.

$* *$ A set of parameters including net oxygen production $\left(A^{\mathrm{O}_{2}}\right)$, chlorophyll-a production, biomass, as distinguished from other regularly-measured parameters, such as temperature, salinity, $\mathrm{pH}$, dissolved oxygen, alkalinity, dissolved and particulate nutrients. 
Table 1

Net oxygen production and outlet nutrient concentrations for elevated nutrient experiment (mean \pm standard error; no. of cases in brackets)

\begin{tabular}{|c|c|c|c|c|}
\hline Condition & $\Delta \mathrm{O}_{2}\left(\mathrm{~m}^{\prime} 1^{-1}\right)$ & $\mathrm{PO}_{4}\left(\mu \mathrm{g}\right.$-at $\left.\mathrm{P}^{-1}\right)$ & $\mathrm{NH}_{3}\left(\mu \mathrm{g}\right.$-at $\left.\mathrm{N}^{-1}\right)$ & $\mathrm{NO}_{3}\left(\mu \mathrm{g}-\mathrm{at} \mathrm{N} \mathrm{l}^{-1}\right)$ \\
\hline \multicolumn{5}{|c|}{ During nutrient addition } \\
\hline $\begin{array}{l}\text { control } \\
\text { elev-P } \\
\text { elev-N }\end{array}$ & $\begin{array}{l}0.90 \pm 0.04(36) \\
1.38 \pm 0.06(35) \\
1.36 \pm 0.05(36)\end{array}$ & $\begin{array}{l}0.11 \pm 0.01(18) \\
5.45 \pm 0.42(35) \\
0.20 \pm 0.03(36)\end{array}$ & $\begin{array}{l}2.98 \pm 0.34(18) \\
1.98 \pm 0.20(36) \\
6.55 \pm 0.32(35)\end{array}$ & $\begin{array}{l}0.32 \pm 0.03(18) \\
0.28 \pm 0.02(36) \\
0.26 \pm 0.02(36)\end{array}$ \\
\hline $\begin{array}{l}\text { control } \\
\text { elev-P } \\
\text { elev-N }\end{array}$ & $\begin{array}{l}\text { nutrient addition } \\
0.93 \pm 0.04(46) \\
1.45 \pm 0.06(50) \\
1.12 \pm 0.04(50)\end{array}$ & ceased & & \\
\hline
\end{tabular}

significant changes in nitrate- $\mathrm{N}$ concentrations. The fact that, for the phosphate tanks, significantly increased $\Delta \mathrm{O}_{2}$ continued 3 to 4 months after all nutrient additions ceased is of greatest interest. This observation suggests that intact microcosm communities are "leaky" to nitrogen but operate to conserve phosphate even in the $101 \mathrm{~min}^{-1}$ flow-through situation. Both observations are entirely consistent with field observations made on reef-flat communities (Pilson, 1973; Pameroy, 1974).
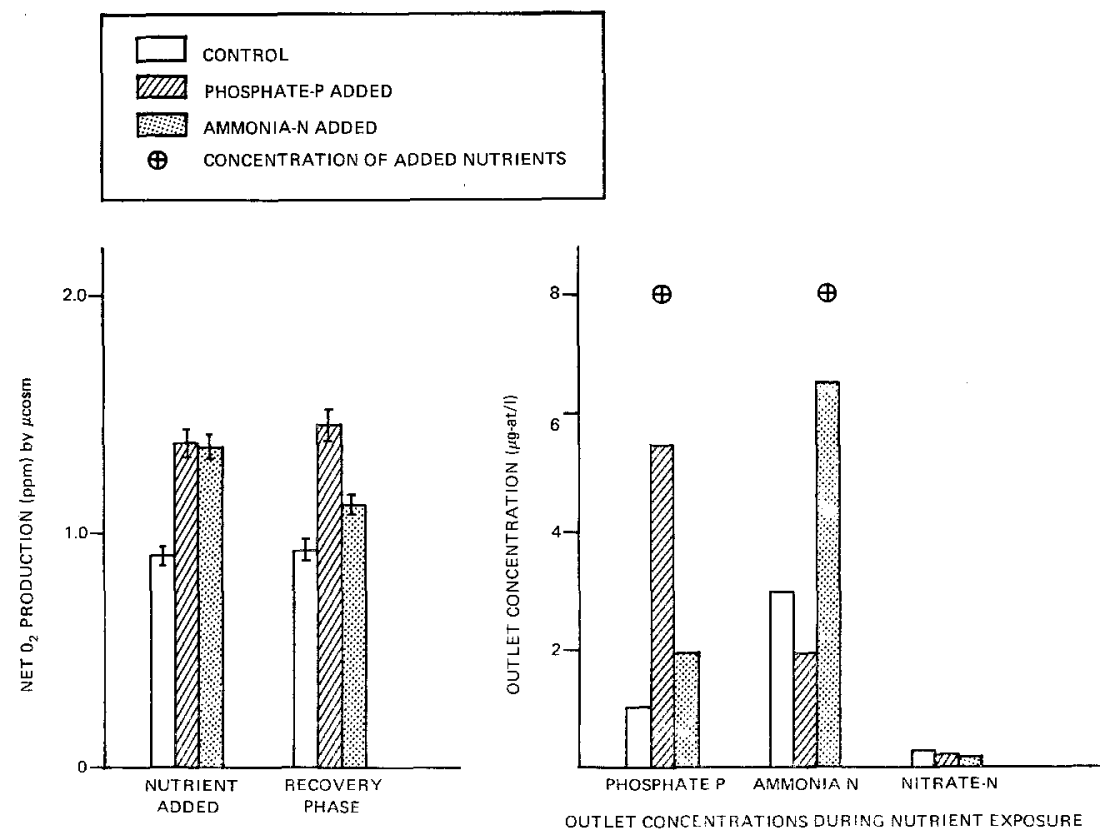

Fig. 4: Plct of net oxygen production and of nutrient concentrations of the elevated-nutrient microcosm experiment 


\section{Copper toxicity}

A second example of the use of established microcosms to determine community response to a given perturbant is provided by the copper toxicity series. Field surveys have often associated elevated copper concentrations with ships and shipyard activity (Evans, 1974) and with discharged cooling waters (Chesher, 1971). The effect of copper on marine communities was therefore investigated. In this instance, six 9-monthold naturally-recruited microcosms were augmented by the addition of two planktivorous fish (Dascyllus albisella), two herbivorous fish (Scarus sordidus), five small colonies each of two hermatypic corals (Pocillopora damicornis and Montipora verrucosa), and four to seven tunicates (Ascidia sydneiensis and $A$. interrupta). The naturally-recruited community included the anemone Aiptasia diaphana, whose importance will be seen. Copper (added as $\mathrm{CuSO}_{4}$ ) was bled into the inlet boxes to produce copper concentrations in the flow-through waters ranging from acute $\left(10 \mathrm{mg} \mathrm{l}^{-1}\right)$ to slightly above coastal ambient $\left(0.01 \mathrm{mg} \mathrm{l}^{-1}\right)$.

At exposures of $0.1 \mathrm{mg}^{1-1}$ or greater all corals died on the first day. Corals exposed to $0.01 \mathrm{mg}^{-1}$ were under severe stress (polyps withdrawn and whitened) by the second day and were dead on the sixth. Copper exposures of $1.0 \mathrm{mg}^{-1}$ or greater killed all fish on the first day; indeed, at the two higher copper exposures there were no survivors. Fish in the 0.1 and 0.01 exposure tanks survived for the duration of the elevated copper treatment (170 days). Although grazing on algae was not obvious in the $0.1 \mathrm{mg} \mathrm{I}^{-1}$ tank, the resident fish showed no loss of weight. Among the naturallyrecruited population, many xanthid crabs and alpheid shrimp also survived the full 170 days of 0.1 and 0.01 exposures.

Aiptasia diaphana could not survive in the $0.1 \mathrm{mg} \mathrm{l}^{-1}$ tank; only three animals were alive at two weeks, and these were severely stressed (characteristically bluish color and tightly retracted tentacles). At the 0.01 exposure, these animals responded in a manner suggesting that they could make good bioindicators of copper or heavymetal pollution. Some of the population present at the start of the $0.01 \mathrm{mg}^{-1}$ copper exposure survived 62 days. A few small animals were found at the termination of the copper exposure (170 days), but these may have settled during the exposure. Surviving animals were severely stressed and, interestingly, could only be found in heavily shaded areas of the microcosms. Preference for the shade has also been reported for tunicates under copper stress (Chesher, 1971). A. diaphana contain zooxanthellae, a symbiotic dinoflagellate which may be nutritionally important to the anemone. Some tunicates contain symbiotic algae, perhaps important to their nutrition (Smith, 1935). It is also reported that copper is more toxic to algae when photosynthesizing (Chesher, 1971; Steeman Nielsen, 1970). Possibly a shaded situation has certain real advantages to these animals when under copper stress. Field evaluations of the anemone were immediately initiated as a result of these observations first made in the microcosms.

The algal component of the microcosms showed a pronounced response to copper concentration. Algal stands on the walls of the control tanks were $75 \%$ blue-greens (Rivulariaceae and Oscillatoriaceae), $20 \%$ greens (Cladophora spp.), and the rest diatoms, browns, reds, and some organic debris. In the $0.01 \mathrm{mg} \mathrm{l}^{-1}$ tank, composition changed to $40 \%$ organic detritus, $30 \%$ blue-greens (Rivulariaceae), $20 \%$ 


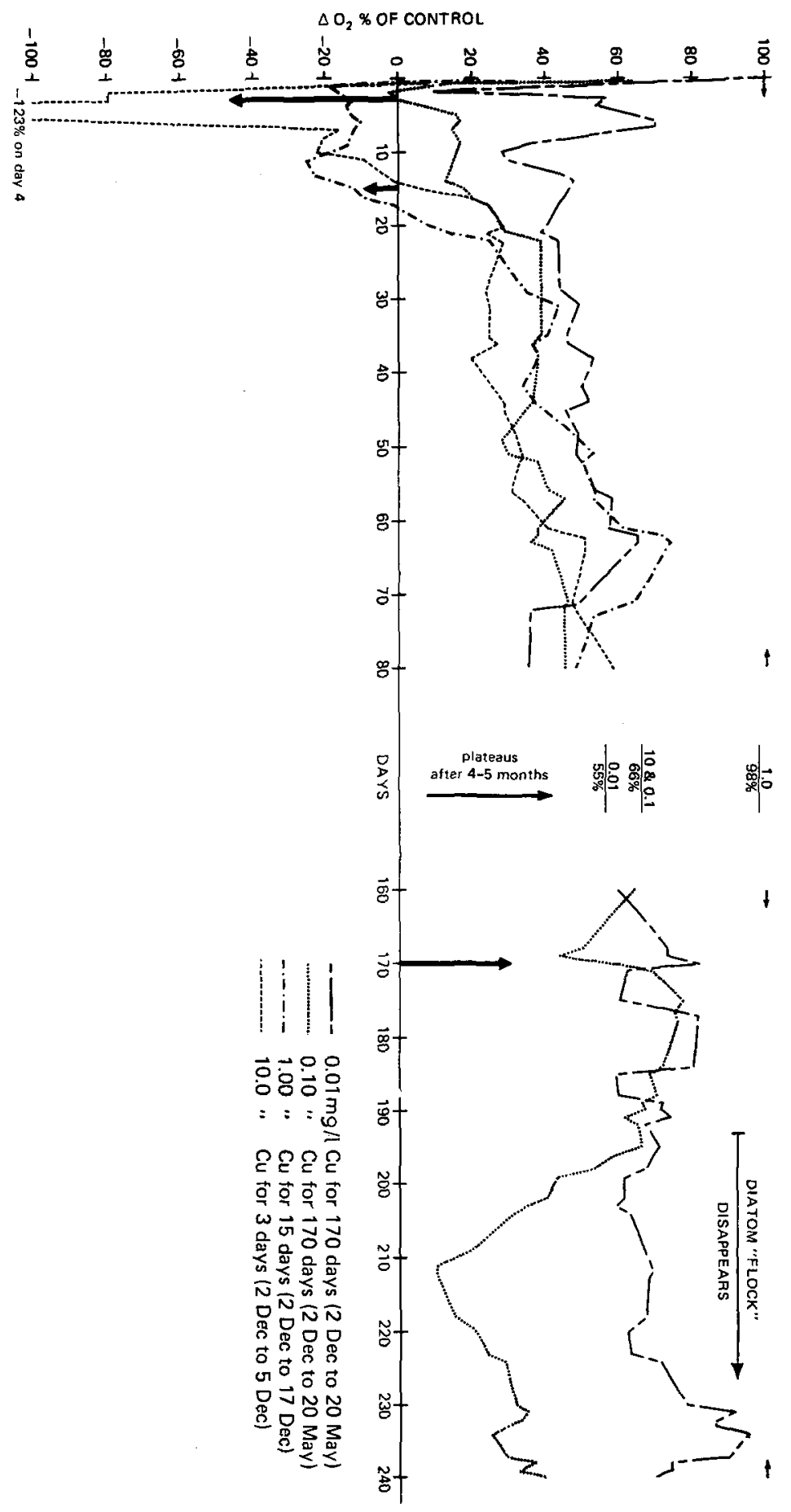


diatoms, with an appreciable stand of Padina, a brown algae rare in all other microcosms, including the controls. In the $0.1 \mathrm{mg} \mathrm{l}^{-1}$ tank the walls were covered to a depth of 2 to 3 centimeters with what is best described as a diatom flock. This flock was composed of about $20 \%$ diatoms, the rest being organic detritus. Herbivorous fish resident in this microcosm would not graze on this material. A similar flock has also been observed on surfaces in Pearl Harbor. In the microcosms, the accumulation of flock became so thick that it sluffed off and floated out of the tank on the flowthrough current, suggesting that it may be the source of "marine snow" often reported in the waters of heavily-utilized harbors.

The net oxygen production $\left(\mathrm{O}_{2}\right)$ for the microcosms was followed on a regular basis both during the copper exposures and for many months after exposure had terminated. The acute copper exposure $(10 \mathrm{ppm})$ was terminated at 3 days; the $1.0 \mathrm{mg} 1^{-1}$ exposure, at 15 days. Recovery of both these microcosms was followed for 6 months. The two lower exposures $\left(0.1\right.$ and $\left.0.01 \mathrm{mg} \mathrm{1}^{-1}\right)$ were continued for $5^{1 / 2}$ months, after which their recovery was followed for over 2 months. The pertinent sections of the $\mathrm{AO}_{2}$ plots are presented in Figure 5. The values are expressed as a percentage of the control $\Delta \mathrm{O}_{2}$ which was measured at essentially the same time. Since ambient dissolved oxygen in Ulupau supply waters is normally between $61 / 2$ and $7 \mathrm{mg} \mathrm{1-1}$, large negative values of $\Delta \mathrm{O}_{2}$ are possible from a moribund or recentlydead microcosm. These are indeed seen in the $10 \mathrm{mg} \mathrm{l}^{-1}$ microcosm. Note that both the 1 and the $10 \mathrm{mg}^{-1}$ exposures apparently inhibit decomposition of organisms killed but not yet rinsed out of the system; hence, the sharp negative spike in $\mathrm{AO}_{2}$ at 3 days when the $10 \mathrm{mg} \mathrm{I}^{-1}$ exposure was terminated. The negative spike does not occur when the $1 \mathrm{mg} \mathrm{l}^{-1}$ exposure was terminated at 15 days, presumably because much of the dead material had by then been rinsed out of the microcosm. The $1 \mathrm{mg} \mathrm{l}^{-1}$ microcosm recovered nearly completely after 5 months, while the $10 \mathrm{mg} \mathrm{l}^{-1}$ microcosm plateaued at approximately $66 \%$ of control in about the same time. The two remaining microcosms which were still receiving 0.1 and $0.01 \mathrm{mg}^{-1}$ of copper continuously, plateaued at $66 \%$ and $55 \%$ of control respectively after about 4 months. The "crash" of the $0.1 \mathrm{mg} \mathrm{I}^{-1}$ microcosm 3 weeks after the copper addition was terminated at 170 days was not expected. That this "crash" is indeed due to the cessation of copper additions is strongly suggested by the disappearance of the diatom flock mentioned above at the same time. Certainly the differences between the microcosm reactions shown in Figure 5 and standard 96-hour $\mathrm{LC}_{50}$ tests can readily be appreciated.

\section{Panel transfers}

Fouling or aufwuchs communities have often been used as indicators of general environmental conditions (Krock, 1971; Reish, 1971). Fouling has the advantages of being nearly omnipresent but has the disadvantages of high seasonal "noise". In order to develop fouling as a useful bioindicator system, panel transfer experiments utilizing the microcosm tanks were initiated. These transfer experiments provide a good example of the second way in which the Navy microcosm facility is used.

Panels of gray PVC plastic $(18$ by $20 \mathrm{~cm}$ ) were suspended from the Fuel Pier, 

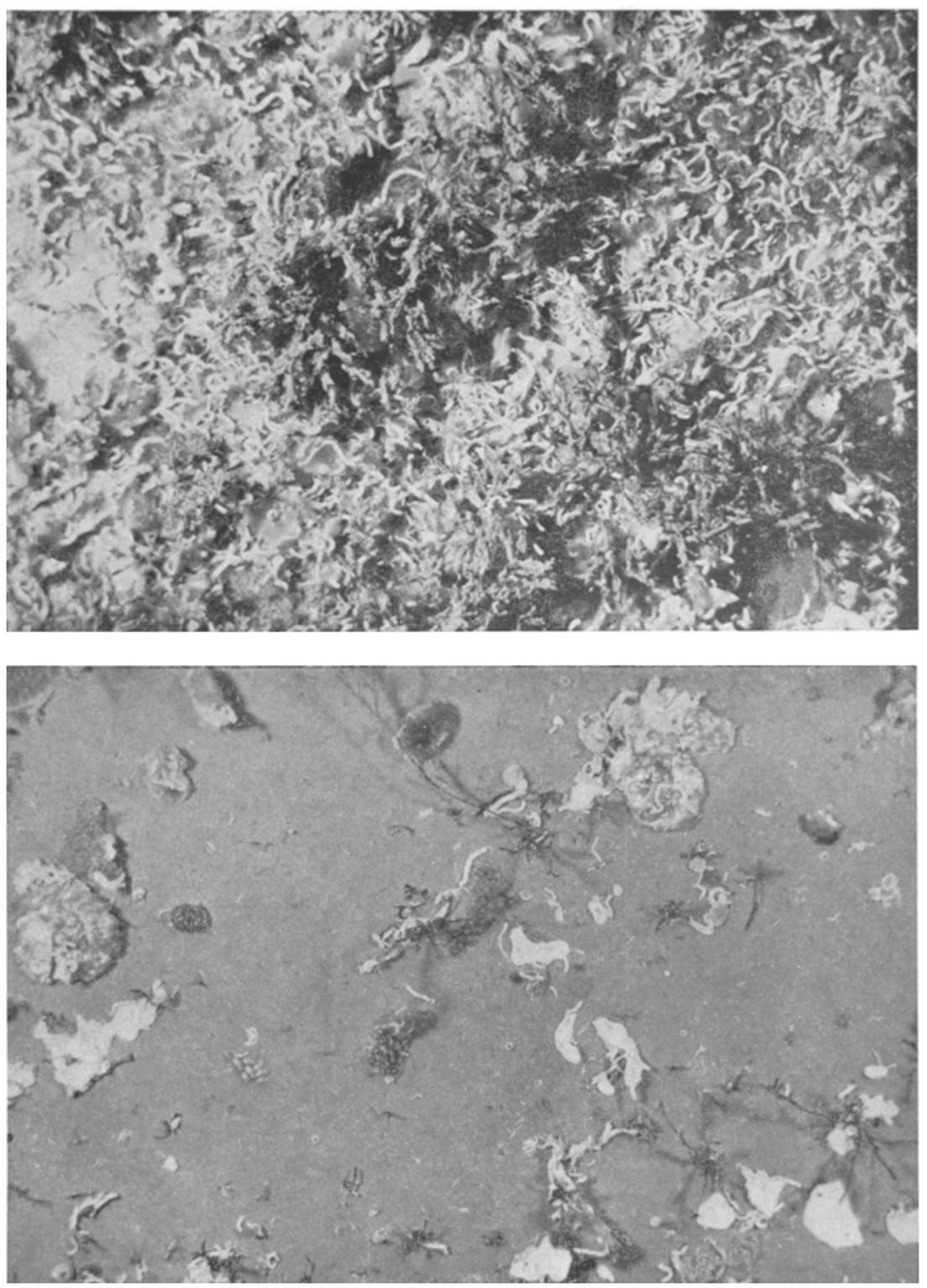

Fig. 6: PVC fouling panel. Above: Upon removal after 61-day settlement period in Kaneohe Bay. Below : after subsequent 12 days in Ulupau microcosm tank

a nutrient rich environment in Kaneohe Bay, for 61 days. Dominant among the naturally-recruited fouling community were Hydroides elegans $(=H$. norvegica), Bugula neritina, and several species of ascidians and barnacles (Fig. 6A). After 61 days at the Fuel Pier, the settled panels were gently transferred in special containers to 
Ulupau where they were placed in microcosms supplied with ocean source water at $101 \mathrm{~min}^{-1}$. Figure $6 \mathrm{~B}$ shows the same 13 by $18-\mathrm{cm}$ panel area after 12 days in ocean source water. Position can be checked by means of the small reddish tunicate, Polyclinum sp., at left center. Better than $90 \%$ of the biomass, much of it originally cemented to the surface, has fallen from the panel. The dramatic change is not due to flexing of the panel or other disturbance during transport; it is presumed due to starvation, followed possibly by chemical solution of certain biogenic cements. Barnacle cements, for instance, seem resistant since tests remain long after the animal has died.

These impressive transformations have been repeated several times, both with smooth PVC panels and with rough asbestos panels. Fuel Pier panels transferred to the Hawaii Institute microcosms, which are supplied with high-nutrient bay waters, react quite differently. They remain relatively unchanged if grazing fish (here Acanthurus xanthopterus) are not members of the microcosm. The loss of fouling communitics is thus definitely nutrient related; however, such factors as recruitment, water quality (defined by any of the numerous conventions), and other biological parameters must be involved. The particular advantages of these transfer experiments are that water quality at both settling and transfer sites can be precisely defined, transfers can be replicated and replications can be repeated at many seasons. Thus, a good statistical basis can be obtained for correlating fouling community response to known environmental conditions. Microcosms, then, become efficient tools for sorting out potential bioindicators among the usually complex fouling communities. Promising organisms can then be checked in the field.

\section{Sediment infaunatransfers}

A second example of a transfer experiment is provided by a series designed to determine the effects of bioturbic action on nutrient or heavy metal exchange rates between bottom sediments and the water column. SCUBA divers operating on the bottom gently scooped soft sediment with its resident infauna into a 14-1 bucket which was immediately taken to the surface. There, the sediment was "slid" into highdensity polyethylene "tote boxes" covered $74 \%$ of the tank bottom. The remaining tank bottom, accomodating plumbing inlets and outlets, was covered with clean beach sand to the level of the boxes. The microcosm tanks were covered with four plys of $2 \mathrm{~mm}$ mesh, gray-plastic screen, which reduced light in the tanks to $121 / 2 \%$ of ambient daylight. Normal burrowing of the infaunal community was resumed within a day of the transfer. The dominant burrowing animal in collections from Kaneohe Bay is the shrimp Alpheus mackayi. From microcosms observations, it was determined that this shrimp makes $26 \pm 5$ burrow-entrances per individual. Although their burrowing activity was calculated to increase sediment surface area by 2 - to 3 -fold, no increases could be detected in flow-

* Tote box dimensions were $47 \mathrm{~cm}$ by $31 \mathrm{~cm}$ by $101 / 2 \mathrm{~cm}$ deep; volume is 151.141 of sediment filled them to within about a centimeter of the top. The boxes are supplied by the United States Plastics Corp, Lima, Ohio. 
through water concentrations of ammonia-N, nitrate-N, or phosphate-P. Microcores taken at the collection sites in Kaneohe Bay and in the microcosm itself did, however, show nutrient losses from interstitial waters near the surface of the microcosm sediments. This loss was not consistently seen in the microcores from the field, suggesting that accelerated losses were indeed occurring in the microcosm.

Other aspects of these experiments are perhaps of greater interest. Alpheid activity was observed to have profound effects on bottom microtopography. In addition to the obvious burrows, their activity quickly masked mounds and tracks made by smaller infaunal residents. These features cannot be seen in the field, and appeared only during the first few days after the transfer when the resident shrimp tended to avoid the surface probably because of their new surroundings. Shrimp grazing or the frequency of their movements over the surface also removed a brownish diatom mat which covered the bottom in their absence. Although the constant "rain" of organic detritus characteristic of the Kaneohe Bay sites where the sediments were collected was obviously absent, the resident alpheids either found sufficient food in the sediments or switched to an alternate source since all animals captured survived a 92-day experiment. In fact, the resident infaunal population per unit volume of these nutrient-rich Kaneohe Bay sediments increased 5- to 10-fold during the better-than-3-month period they were maintained in Ulupau source water. These nutrient-rich sediments appeared to be acting as an analogue to an "artificial reef". Relatively unoccupied substrate from Kaneohe Bay, when placed in the near-oceanic enviroment extant in the Ulupau microcosms, acquired an enhanced infaunal population, either by increased reproduction in that already resident or by settlement from the supply waters. Water conditions at the original collection sites probably operated to reduce substrate residency. When transferred to the Ulupau facility, these same substrates caused no detectible changes in water-column nutrient concentrations but did acquire a significantly increased infaunal population.

Sediment transfer work neatly complements the fouling panel transfers reported above. Both can be used in an expanded search for reliable bioindicator systems. Furthermore, if the population increases can by substantiated through additional "polluted" sediment transfers, the widely-accepted negative attitude toward disposal of dredge materials may require careful re-examination.

\section{DISCUSSION}

The thrust of this presentation has been somewhat different from the usual paper. The intent has been to describe a few important innovations at a newly constructed facility capable of maintaining microcosms which closely resemble shallow-water reef or harbor communities, and then to show be means of four examples how microcosm experimentation can complement and indeed extend surveys in the field. In the past, research has tended to be limited to studies within the microcosm itself. This discussion emphasizes the extended use of microcosms.

The use of "stagnation" cleaning and the flow-regulating system employed at the Ulupau microcosm facility need no further discussion here, nor do the four ex- 
perimental series described above, since the pertinent discussion has been included with the results. The elevated-nutrient experiments using microcosms were actually part of a larger survey being conducted to determine the effects of sewage in two Hawaiian estuaries, viz. Kaneohe Bay and Pearl Harbor. The environmental stresses in these two water bodies are different. In Kaneohe Bay, the anthropogenic stress gradient is essentially elevated nutrients, while in Pearl Harbor that gradient is complicated by an added heavy-metal gradient. It has been shown elsewhere (Evans, 1974) that there is a very high statistical correlation between copper and certain other heavy metals, such as cadmium, lead, mercury, and zinc.

Panel transfer experiments using the microcosms have shown fouling communities to be an indicator system responsive to the nutrient status of the water column. Copper-toxicity experiments, using naturally-recruited microcosms have indicated at least one sensitive bioindicator of elevated copper concentrations, viz. Aiptasia diaphana. Subsequent field surveys using this animal have shown it to be insensitive to nutrient status. It is found, for instance, from moderate to just-subtidal depths throughout Kaneohe Bay, regardless of location relative to the nutrient gradient. Its distribution in Pearl Harbor is, however, quite striking. Just at the harbor entrance, the anemone is found in its normal state and at its characteristic moderate to just-subtidal depths. About midway into the harbor (Hospital Point) it is not found at depths shallower than 1 meter and is showing obvious signs of stress. Well into the harbor (Merry Point) it is found only on or near the bottom at $3 \mathrm{~m}$ depth and has lost all zooxanthellae. Presumably, the animal is able to survive without its symbiotic partner in the nutrientrich bottom environment extant at Merry Point. Microcosm experimentation, in combination with field survey, has produced a series of results, which can lead to the determination of cause and effect in these complex marine environments ... environments which should not always be separated into experimentally convenient subunits. Communicy tolerance and recovery capacity, naturally available foods and recruitment populations, various combinations of anthropogenic perturbants, ambient water quality, and seasonal events, all are interactive components of the environment under survey. Further work using both microcosms and field surveys in a coordinated research program cannot help but improve our understanding of harbor environments, both stressed and otherwise.

In closing, it should be said that only the use of microcosms as an extension of field surveys has been discussed here. These are two aspects of a larger Navy program in environmental research that has been described elsewhere (Hura, 1976).

Acknowledgements. This work was conducted on funds from the Naval Engineering Facilities Command (NFAC-032B), from the Office of Naval Research (ONR-443), and from an Environmental Protection Agency grant. The work summarized here represents the efforts of many, particularly: J. G. Grovhoug, R. S. Henderson, and S. V. Smith. The invaluable assistance of many students of the University of Hawaii also deserves special mention, particularly: D. K. Barclay, R. M. Cutts, K. Klein, L. Neu, E. B. Ratstetter, and J. A. Toth. To these and to many others $I$ give my deepest thanks. 


\section{LITERATURE CITED}

Chesher, R. H., 1971. Biological impact of a large-scale desalination plant at Key West. EPA Water Pollution Control Research Series 18080 GBX 12/71.

Evans III, E. C., 1974. Pearl Harbor biological survey. Final Rep., NUC TN-1128.

Henderson, R. S., Evans III, E. C. \& Smith, S. V., 1976. Flow-trough microcosms for simulation of marine ecosystems: Development and intercomparison of open coast and bay facilities. NUC TP-519.

Hura, M., Evans III, E. C. \& Wood, F. G., 1976. Coastal water protection the navy way. Environmental Science \& Technology 10, 1098-1103.

Krock, H. A. \& Mason, D. T., 1971. Bioassays of lower trophic levels. In: A study of toxicity \& biostimulation in San Francisco Bay-Delta waters. Vol. 4. SERL Rep. Univ. of California 71-8.

Monod, J., 1950. La technique de culture continue. Annls Inst. Pasteur, Paris, 79, 390-410.

Pameroy, L. R., Pilson, M. E. Q. \& Wiebe, W. J., 1974. Tracer studies of the exchange of phosphate between reef water and organisms on the windward reef of Eniwetok Atoll. In: Proceedings of the 2 nd international symposium on corals and coral reefs. Great Barrier Reef Comm., Brisbane, 1, 87-96.

Pilson, M. E. Q. \& Betzer, S. B., 1973. Phosphate flux across a coral reef. Ecology 54, $581-588$.

Reish, D. J., 1971: Effects of pollution abatement on Los Angeles harbours. Mar. Pollut. Bull. $2,71-74$.

Smith, H. G., 1935: On the presence of algae in certain Ascidiacea. Ann. Mag. nat. Hist. (Ser. 10) 15, 615-626.

Steeman Nielsen, E. \& Wium-Andersen, S., 1970: Copper ions as poison in the sea and in freshwater. Mar. Biol. 6, 93-97.

Author's address: Dr. Evan C. Evans III

Marine Environmental Management Office

Naval Undersea Center, Hawaii Laboratory

P. O. Box 997

Kailua, Hawaii 96734

USA 